\title{
INFLUENCE OF TURBIDITY ON SURVIVAL OF WHITE LEG SHRIMP (LITOPENAEUS VANNAMEI) GROW OUT PHASE IN SPSR NELLORE DISTRICT, ANDHRA PRADESH, INDIA.
}

\section{Suneel Bommireddy ${ }^{1}$, Sumanth Kumar K. ${ }^{2}$, Anand Prasad, P. ${ }^{3}$, Chandrasekhara Rao, A. ${ }^{4}$}

1Ph.D Scholar, Department of Zoology and Aquaculture, Acharya Nagarjuna University, Nagarjuna Nagar - 522 510, A.P., India.

2Associate Professor, Department of Zoology and Aquaculture, Acharya Nagarjuna University, Nagarjuna Nagar - 522510 , A.P., India. 3Assistant Professor, Department of Aquaculture, College of Fishery Science, Muthukur, Nellore, A.P., India.

4 Principal, S.M.V.K.R. Polytechnic college, Bavadevarapalli, Krishna, A. P., India

\begin{abstract}
In the Kandaleru creek area turbidity plays a major role in the survival of shrimp in culture ponds. The turbidity effect on survival rates was analyzed in the present study. The treatment ponds R1, R2, and R3 were fed with clear water which was resulted from flocculation sedimentation and treatment, and were compared against the Control (C) which was fed with creek water directly. Survival and turbidity of Litopaeneus vannamei ponds were observed for two years (4, crops) and the highest survival was observed in crop 3, (R1 and R3 treatments) and the lowest was recorded in crop 4 (control). Turbidity in control ponds was varying from $36.19 \pm 7.0470$ to $47.65 \pm 4.009$ NTU and in treatment ponds $4.38 \pm 0.616$ to $6.02 \pm 0.906$ NTU. Even though the turbidity in the treatment ponds $(6.02 \pm 0.906$ NTU) was not much varied but highest survival \% was (91.9415 $\pm 0.070 ; 91.9415 \pm 0.013$ ) coinciding with R1 and R3 of crop -3 (February - May) 2017 - 18. In each crop, the lowest survival \% (81.6104 \pm 1.16 to $84.2207 \pm 0.03)$ was recorded in control ponds which were fed with higher furbidity compared to the treatments.
\end{abstract}

Keywords: Turbidity, Survival, Litopenaeus vannamei, Grow out ponds, Crops 


\section{Introduction}

The growth of both rural and industrial aquaculture development is needed for the wellbeing of the sector as a whole. The aquaculture sector has been the target of much criticism from environmental groups, whose content has been exaggerated or ill-founded, more often than not (De Silva, S.S. 2001). High intensification of shrimp rearing practices in the recent past resulted in a high influx of organic load, sediments, and associated, increase stress levels on the aquatic organisms led to severe disease outbreaks and ready to collapse stage of aquaculture. The spread and intensification of shrimp farming and poor management practices caused diseases and thereby significant losses to the farmer. The survival and sustainability of the industry will be determined primarily by the modus operandi of the operating practices, which will, by necessity have to be environmentally acceptable (Beveridge et al.,1997). Despite these limitations, an attempt has been made here to address the turbidity influence on the survival factor of Litopenaeus vannamei in the grow-out ponds.

\section{Materials and methods}

The experimental site was located nearby the banks of Kandalery Creek (14022'44.98' $\mathrm{N}$ 80०06'39.41' 'E), in the Nellore district of Andhra Pradesh. The experimental setup was made in such a way that the treatment ponds R1, R2, and R3 were fed with clear water which was resulted from flocculation sedimentation and treatment, and were compared against the Control (C) pond, which was fed with creek water directly, and also these ponds were seeded with the same density of the L. vannamei. These ponds were filled with brackish water as a source of water. The present study was carried out for four crops (from FebruaryMay \& September-December) of the years, 2016-18.

The turbidity was measured weekly using a turbidity meter (Hach 2100P Hack Company, Loveland, CO, United States). The reagent powder pillows and Hach spectrophotometer 2800 provided by Hach Company (Hach Company 2002) were used in the determination.

Growth parameters were analyzed at regular intervals starting from the $35^{\text {th }}$ day to till harvest. After harvest, the survival rates were estimated. During the growth trial, all water quality parameters were similar except the turbidity.

The raw data obtained on survival and turbidity were analyzed by using descriptive statistics and univariate analysis of variance and also by utilizing statistical software (or) package SPSS 16.0. version.

\section{Results and discussion}

Water turbidity refers to the quantity of suspended material, which interferes with light penetration in the water column. Turbidity limits light penetration thereby limiting photosynthesis in the pond. Higher turbidity can cause temperature and DO stratification in shrimp ponds (Boyd, 1990). In the present study the turbidity in the treatment ponds was in the range of $4.38 \pm 0.616$ to $6.02 \pm 0.906$ NTU (Fig. 1) and in the control pond $36.19 \pm 7.047$ to $47.65 \pm 4.009$ NTU (Fig.1) throughout the experimental periods in different crops. In the present study flocculation/ coagulation with PAC (Poly aluminum chloride) and sedimentation might have played a significant role in reducing total 
suspended solids in the water and indirectly bringing down the turbidity in treatment ponds with final concentrations of suspended solids less than $10 \mathrm{mg} / \mathrm{L}$. Fakhri et al., 2015 also observed a decrease of TSS in treatment ponds compared to control ponds. Treatment of pond water with flocculating agents and sedimentation for the rearing of shrimps by managing the concentration of TSS (Total suspended solids) gave beneficial results (Ebeling et al., 2006; Cohen et al., 2005; Schryver et al., 2008). As solids increase, so does biochemical oxygen demand potentially leading to decreased oxygen availability for shrimp (Beveridge et al., 1991), both coagulation-flocculation aids also exhibited excellent settling.

J.M. Ebeling et al., (2006) opined that the majority of the floc quickly settling out in the first 5 min. Ebeling et al., (2005) reported TSS removal was close to $99 \%$ settling by application of flocculating agents. According to the results of this study, all factors of water-quality parameters were at optimum levels in the experimental ponds compared with the control. However, the application of flocculating agents, sedimentation, and treatment of water drastically brought changes in turbidity of treatment pond water, which indirectly influenced the beneficial algal growth and improved water quality conditions resulted in growth rate, and survival, the productivity of vannamei in treatment ponds.

According to the results of this study, all factors of water-quality parameters were at optimum levels in the experimental ponds compared with the control. However, the application of flocculating agents, sedimentation, and treatment of water drastically brought changes in turbidity of treatment pond water which indirectly influenced the beneficial algal growth and improved water quality conditions resulted in growth rate, and survival, the productivity of vannamei in treatment ponds.

The low turbidity values were observed in treatments R1, R2, and R3 than the control where the water source was used after sedimentation $15 \mathrm{mg} / \mathrm{L}$. PAC dose) and disinfection with chlorine. However, might be the turbidity that finally played a major role in the survival of vannamei, as all the other parameters were not much different except turbidity. In this study, feed and water quality parameters were not varied much for all the treatments. If in any case, changes observed were managed within the permissible limits through water exchange.

The survival of the shrimp depends on the water quality of aquatic systems. The suspended solids in the natural water sources leads to stress on the shrimps may reduce the survival in the culture systems. The settling system with effective sedimentation and removal of suspended solids such as feces and uneaten feed enhances the survival of shrimp in the culture system (Gaona et al., 2011). $(87.0619 \pm 1.045 \%)$ In the present study, the highest survival \% observed for the total experimental period was (91.9415 $\pm 0.13 \%$ ) in R1 and R3 of the crop -3 and the lowest $81.6104 \pm 1.16 \%$ in the control pond of crop -4 . The survival \% of shrimp in the treatment ponds was in the range of $87.0619 \pm 1.045$ to $91.9415 \pm 0.13 \%$ (Fig.2) whereas in control ponds $81.6104 \pm 1.16 \%$ to $84.22 \pm 0.03 \%$ (Fig.2). The pairwise comparison of survival \% of vannamei in different treatment ponds showed significance $(p<0.05)$. The pairwise 
comparison of Survival \% of vannamei in different crops was found significant $(p<$ 0.01).

The Mean survival rates of $L$ vannamei in treatment tanks showed an increasing trend than the control (Figure $3)$. The mean survival of $L$. vannamei increased from crop -1 to crop -3 and decreased in crop -4 (Figure -4).

The treatment ponds showed superior significance $(p<0.05)$ in the survival of vannamei when compared to different crops (February to May and September to December). The zero water exchange had significantly more suspended solids compared to treatment ponds and influenced the survival of the shrimp (Samocha et al., 2010). Arantes et al., (2017) demonstrated high survival $(76.9 \pm 6.7 \%)$ in clear waters compared to survival $(57.0 \pm 8.6 \%)$ in zero water exchange ponds. Schvieitzer et al., (2013) observed that concentrations of suspended solids above 800 ppm could cause clogging of the gills and increase shrimp mortality. The results in the present study were correlated with the findings of earlier observations (Ray et al., 2011; Correia et al., 2014). The excess suspended solids in the creek waters can increase the biochemical oxygen demand (BOD) and cause occlusion of the gills of cultivated species (Hargreaves, 2006; McMillan et al., 2003). In the BFT system, the removal of suspended solids is very important because survival depends on the availability of dissolved oxygen and the number of suspended solids in the water column (Hopkins et al. 1995, 1996). According to Ray et al. (2010), the removal of solids can decrease BOD by reducing the stress levels of the shrimp. This results in the process of an increase in survival. Esparza-Leal et al., 2015 were reported significant inverse relation and decreased survival $(85.0 \pm 7.9 \%)$ in the clear water system than the survival $(98.4 \pm 2.4 \%)$ in the zero water exchange system.

\section{Conclusion}

The present study compares the turbidity, shrimp growth parameters, and survival rates during the harvest for 4 crops of the years 2016 to 2018. The growth of the shrimp was monitored once a week from the $35^{\text {th }}$ day of culture. During the sampling, the turbidity measured every week, growth, yield, and survival were assessed at the time of harvest. The correlation between survival and turbidity was inversely significant at a $5 \%$ level of significance.

\section{Acknowledgments}

The authors were highly thankful to the honorable Vice - Chancellor, Acharya Nagarjuna University, Guntur, India for the support rendered in experimenting. This research work is an outcome of Ph. D research work of the first author. 


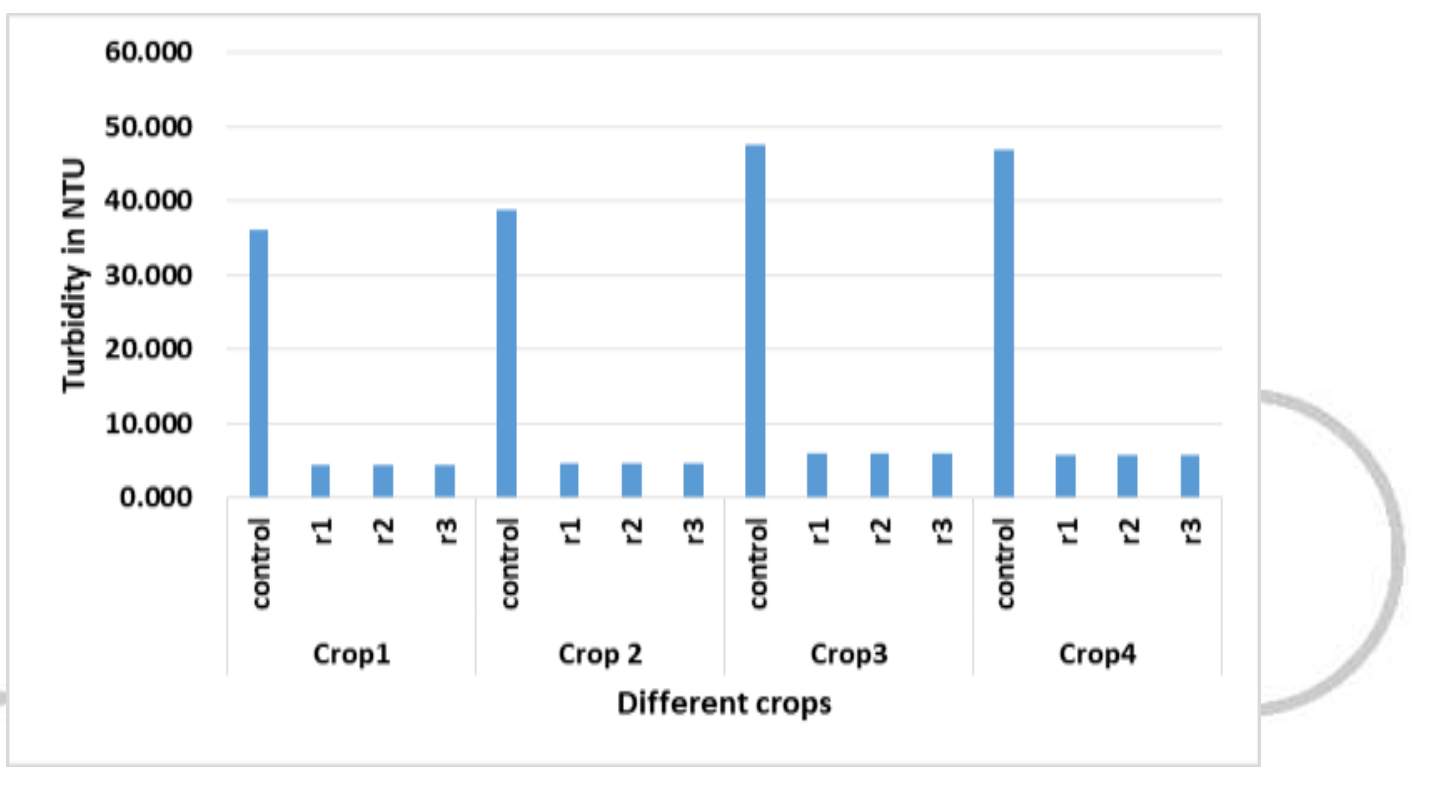

Fig. 1. Turbidity(NTU) in the experimental tanks of $L$. vannamei reared in different crops. 


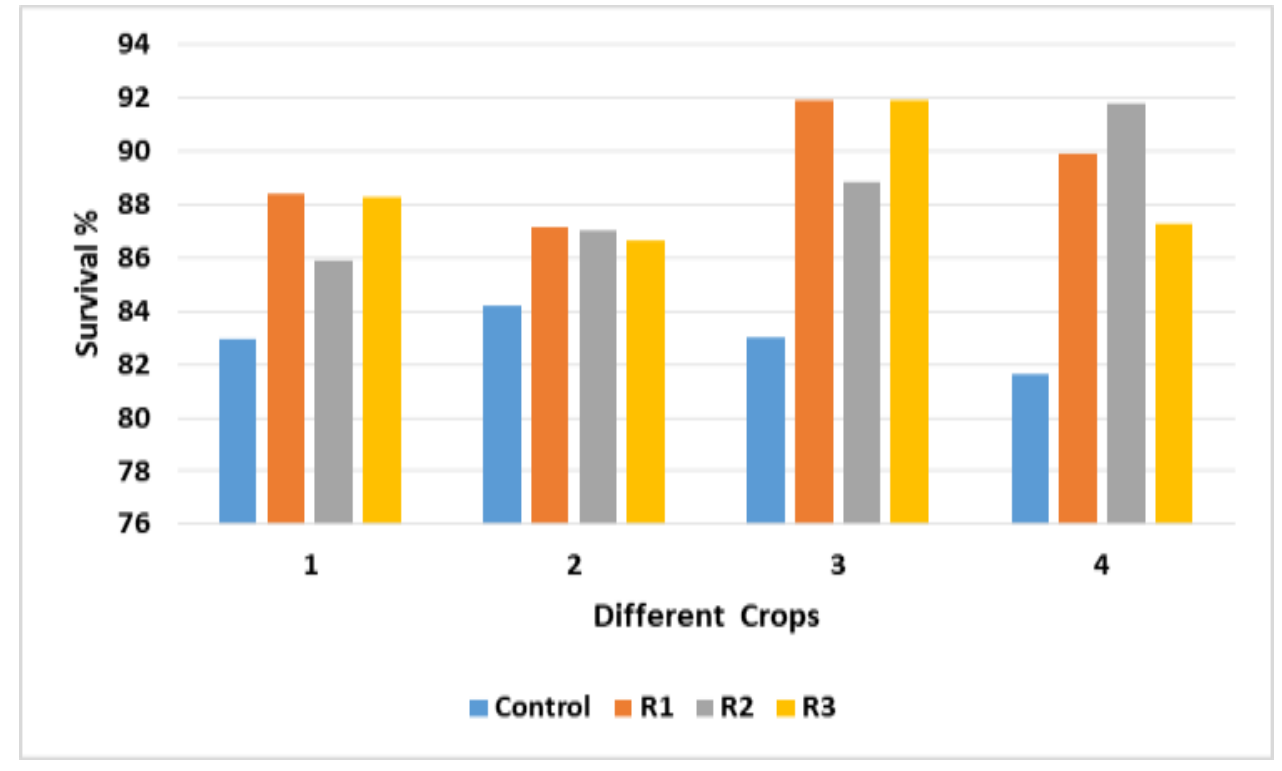

Fig.2. Survival \% in the experimental tanks of $L$. vannamei reared in different crops.

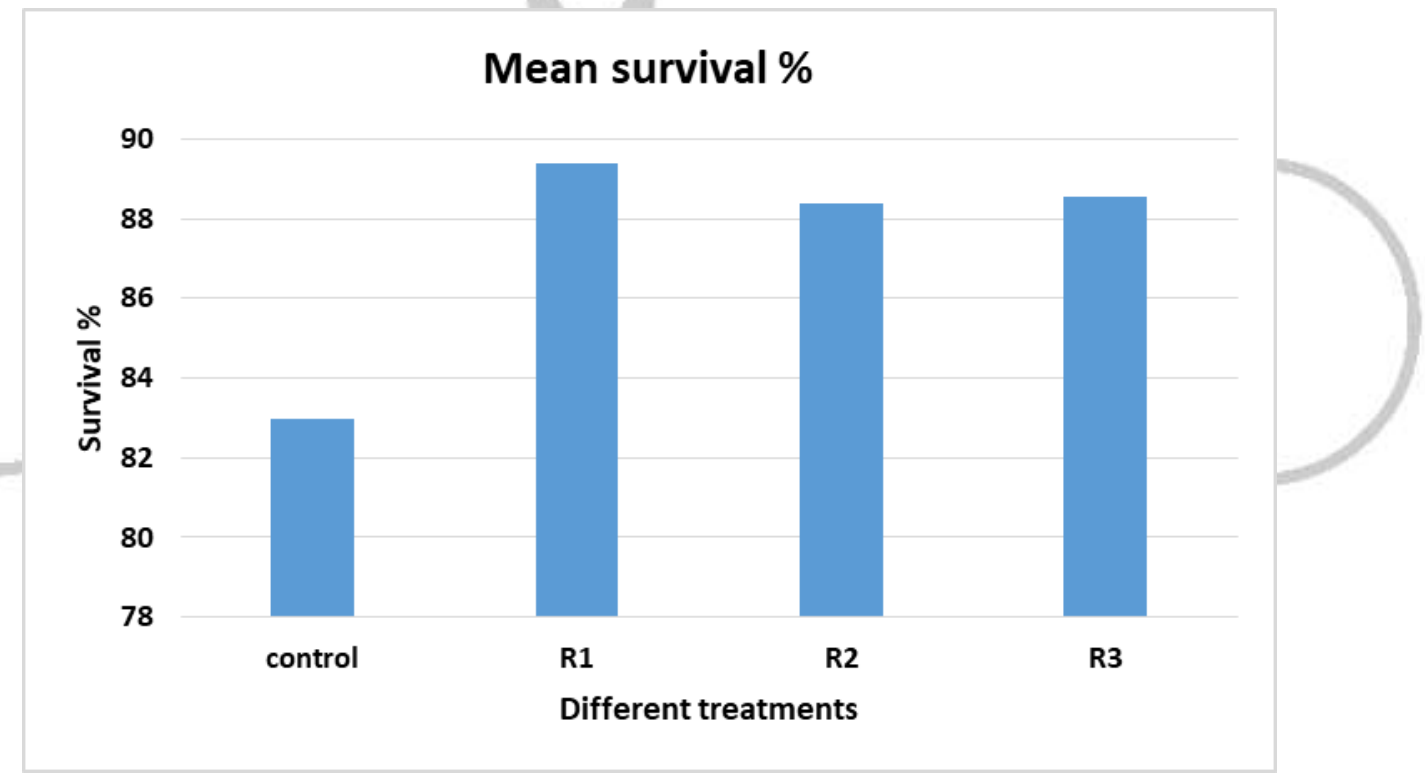

Fig. 3 Mean Survival \% of L. vannamei in different treatments 


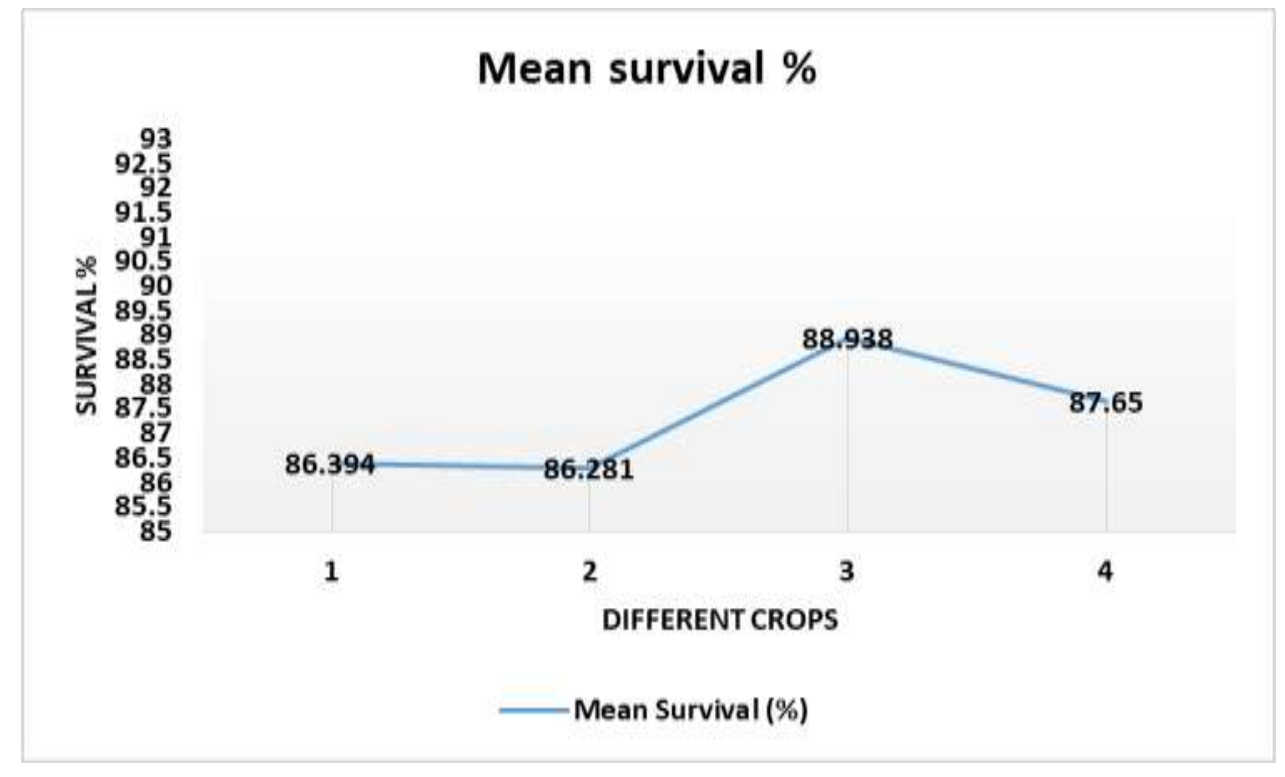

Fig. 4 Mean Survival \% of L. vannamei in different crops

\section{References:}

Beveridge, M. C. M., Phillips, MT, Clarke, R. M., 1991. A quantitative and qualitative assessment of wastes from aquatic animal production. In: Brune, D. E., Tomasso, J. R. (Eds.), Aquaculture and Water Quality. Advances in World Aquaculture, Vol. 3. The World Aquaculture Society, Baton Rouge, Lovisiana pp. 506-533.

Beveridge, M.C.M., Phillips, M.J. \& Macintosh, D.J. 1997. Aquaculture and the environment: the supply and demand for environmental goods and services by Asian aquaculture and the implications for sustainability. Aquacult. Res. 28: 797807.

Boyd, C.E., 1990. Water quality in ponds for aquaculture. Alabama Agricultural Experiment Station, Auburn Univ., Alabama USA., p. 482.
Cohen JM, Samocha TM, Fox JM, Gandy RL \& Lawrence AL, 2005. Characterization of water quality factors during intensive raceway production of juvenile Litopenaeus vannamei using limited discharge and biosecure management tools, Aquaculture Engineering, 32, 425442.

Eudes S. Correia, Joshua S. Wilkenfeld, Timothy C. Morris, Liuzhi Wei, David I. Prangnell, Tzachi M. Samocha, 2014. Intensive nursery production of the Pacific white shrimp Litopenaeus vannamei using two commercial feeds with high and low protein content in a biofloc-dominated system, Aquacultural Engineering, 59, 4854.

De Schryver, P., Crab, R., Defoirdt, T., Boon, N., Verstraete, W., 2008. The basics of bio-flocs technology: the added value for aquaculture. Aquaculture, 277, 125137. 
De Silva, S.S., 2001. A global perspective of aquaculture in the new millennium. In R.P. Subasinghe, P. Bueno, M.J. Phillips, C. Hough, S.E. McGladdery \& J.R. Arthur, eds. Aquaculture in the Third Millennium. Technical Proceedings of the Conference on Aquaculture in the Third Millennium, Bangkok, Thailand, 20-25 February 2000. pp. 431-459. NACA, Bangkok, and FAO, Rome.

Ebeling, James \& Rishel, Kata \& Sibrell, Philip. (2005). Screening and evaluation of polymers as flocculation aids for the treatment of aquacultural effluents. Aquacultural Engineering. 33. 235-249. 10.1016/j.aquaeng.2005.02.001.

Ebeling, James \& Timmons, Michael \& Bisogni, J.J. (2006). Engineering analysis of the stoichiometry of photoautotrophic, autotrophic, and heterotrophic removal of ammonia-nitrogen in aquaculture systems. Aquaculture. 257. 346-358. 10.1016/j.aquaculture.2006.03.019.

Esparza-Leal HM, Cardozo AP, Wasielesky W Jr., (2015). Performance of Litopenaeus vannamei postlarvae reared in indoor nursery tanks at high stocking density in clear-water versus biofloc system. Aquac Eng 68:28-34.

Fakhri, M., Budianto, B., Yuniarti, A. and Hariati, A.M. 2015. Variation in water quality at different intensive white leg shrimp, Litopenaeus vannamei, farms in East Java, Indonesia. Nature Environment and Pollution Technology, 14(1):65-70.

flocs technology: the added value for aquaculture. Aquaculture 277, 125-137. flocs technology: the added value for aquaculture. Aquaculture 277, 125-137.
Gaona, Carlos \& Poersch, Luís \& Krummenauer, Dariano \& Fóes, G.K. \& Wasielesky, Wilson. (2011). The Effect of Solids Removal on Water Quality, Growth, and Survival of Litopenaeus vannamei in a Biofloc Technology Culture System. International Journal of Recirculating Aquaculture. 12. 54-73. 10.21061/ijra.v12i1.1354.

Hargreaves, J.A., 2006. Photosynthetic suspended-growth systems in aquaculture. Aquaculture Engineering 34, 344-363.

Hopkins, J. S., C. L. Browdy, R. D. Hamilton, and J. A. Heffernan., 1995. The effect of low-rate sand filtration coupled with careful feed management on effluent quality, pond water quality, and production of intensive shrimp ponds. Estuaries, 18:116-123.

McMillan, J. \& Wheaton, F. \& Hochheimer, John \& Soares, J., (2003). Pumping effect on particle size in a recirculating aquaculture system. Aquacultural Engineering 27. 53-59.

Paul A. Sandifer, J. Stephen Hopkins, 1996. Conceptual design of a sustainable pond-based shrimp culture system, Aquacultural Engineering, Volume 15, Issue 1, Pages 41-52, ISSN 0144-8609, https://doi.org/10.1016/01448609(95)00003-W.

Rafael Arantes, Rodrigo Schweitzer, Caio Magnotti, Katt Regina Lapa \& Luis Vinatea, (2017) A comparison between water exchange and settling tank as a method for suspended solids management in intensive biofloc technology systems: effects on shrimp 
(Litopenaeus vannamei) performance, water quality, and water use, Aquaculture Research,48, 1478-1490.

Ray, A. J., K. S. Dillon, and J. M. Lotz., 2011. Water quality dynamics and shrimp (Litopenaeus vannamei) production in intensive, mesohaline culture systems with two levels of biofloc management. Aquacultural Engineering, 45(3):127-136.

\section{Ray, Andrew \& Lewis, Beth \& Browdy,} Craig \& Leffler, John., (2010). Suspended solids removal to improve shrimp (Litopenaeus vannamei) production and an evaluation of a plant-based feed in minimal exchange, super-intensive culture systems. Aquaculture. 89-98. 10.1016/j.aquaculture.2009.11.021.

Samocha, Tzachi \& Wilkenfeld, Josh \& Morris, Timothy \& Correia, Eudes \& Hanson, Terry. (2010). Intensive raceways without water exchange analyzed for white shrimp culture. Global Aquaculture Advocate. 13. 22-24.

Schveitzer, Rodrigo \& Arantes, Rafael \& Costódio, Patrícia \& Santo, Carlos \& Vinatea, Luis \& Seiffert, Walter \& Andreatta, Edemar. (2013). Effect of different biofloc levels on microbial activity, water quality and performance of Litopenaeus vannamei in a tank system operated with no water exchange. Aquacultural Engineering, 56. 59-70. 